\title{
Relative Impact of Pain and Fatigue on Work Productivity in Patients with Rheumatoid Arthritis from the RA-BEAM Baricitinib Trial
}

\author{
Kaleb Michaud (D) - Janet E. Pope · Paul Emery • Baojin Zhu • \\ Carol L. Gaich · Amy M. DeLozier · Xiang Zhang · Christina L. Dickson • \\ Josef S. Smolen
}

Received: April 26, 2019 / Published online: June 21, 2019

(C) The Author(s) 2019

\section{ABSTRACT}

Introduction: To explore the relationship of pain and fatigue with daily activity and work productivity in rheumatoid arthritis (RA) patients from the baricitinib clinical trial, RABEAM.

Methods: In RA-BEAM, a double-blind phase 3 study, patients were randomized 3:3:2 to

Enhanced Digital Features To view enhanced digital features for this article go to: https://doi.org/10.6084/ m9.figshare.8235464.

Electronic Supplementary Material The online version of this article (https://doi.org/10.1007/s40744019-0164-4) contains supplementary material, which is available to authorized users.

K. Michaud ( $\square)$

University of Nebraska Medical Center, Omaha, NE, USA

e-mail: kmichaud@unmc.edu

K. Michaud

FORWARD, The National Databank for Rheumatic

Diseases, Wichita, KS, USA

J. E. Pope

Division of Rheumatology, Department of

Medicine, St. Joseph's Health Care, London, Canada

P. Emery

Leeds Institute of Rheumatic and Musculoskeletal

Medicine, University of Leeds and NIHR Leeds

Biomedical Research Centre, The Leeds Teaching

Hospitals Trust, Leeds, UK placebo $(n=488)$, baricitinib $4 \mathrm{mg}$ once daily $(n=487)$, or adalimumab $40 \mathrm{mg}$ biweekly $(n=330)$ with background methotrexate. The Functional Assessment of Chronic Illness Therapy-Fatigue (FACIT-F) measured fatigue and the pain visual analog scale $(0-100 \mathrm{~mm})$ assessed pain. Work Productivity and Activity Impairment Questionnaire-RA measured daily activity and work productivity. At weeks 12 and 24, pain was assessed using pain reduction $(<30 \%, 30 \%$ to $<50 \%, \geq 50 \%$ ) and overall pain score; clinically relevant FACIT-F changes were assessed by values $<3.56$ and $\geq 3.56$ and the FACIT-F normative value score $(<40.1, \geq 40.1)$. Pairwise comparisons between pain/fatigue reduction groups were assessed using ANCOVA with pooled data on daily activity and work productivity. A mediator analysis with pain, fatigue,

B. Zhu · C. L. Gaich · A. M. DeLozier · X. Zhang · C. L. Dickson

Lilly Research Laboratories, Eli Lilly and Company, Indianapolis, IN, USA

\section{J. S. Smolen}

Division of Rheumatology, Department of Medicine

3, Medical University of Vienna, Vienna, Austria

\section{J. S. Smolen}

Department of Medicine, Hietzing Hospital, Vienna, Austria 
and disease activity measured their contribution to daily activity and work productivity. Data were pooled from all patients for most analyses, and baricitinib-treated patients were assessed as a sensitivity analysis.

Results: Reductions in pain ( $\geq 50 \%)$ and fatigue $(\geq 3.56)$ had significant $(p \leq 0.001)$ effects on daily activity and work productivity improvement at weeks 12 and 24. Reductions in pain, fatigue, and disease activity accounted for most of the improvements in daily activity and work productivity. At the lowest levels of remaining pain $(\leq 10 \mathrm{~mm})$ at weeks 12 and 24 , however, fatigue did not appear to impact work productivity. Similar trends were observed with baricitinib-treated patients.

Conclusions: Reductions in pain and fatigue were associated with improved daily activity and work productivity for all RA patients and for baricitinib-treated patients in RA-BEAM.

Trial Registration: ClinicalTrials.gov identifier, NCT01710358.

Funding: Incyte Corporation and Eli Lilly and Company.

Keywords: Baricitinib; Health-related quality of life; Patient-reported outcomes; Work impairment

\section{INTRODUCTION}

Patients rank ability to work as an important treatment outcome because it affects income, living conditions, quality of life (QOL), and the ability to maintain independence $[1,2]$. After the onset of rheumatoid arthritis (RA), a large percentage of patients with RA report impairment in their daily activity and increased issues with presenteeism and absenteeism before their early departure from the work force $[3,4]$. It is estimated that work disability for patients with RA is twice that of the general population [4].

With new therapies for RA, there is an increased interest in controlling disease and improving patients' health-related QOL that will enable patients to function in social and work settings [4]. Patients with RA indicate that pain and fatigue are common and burdensome symptoms of their disease [2], yet it is not clear how much pain and fatigue, evaluated individually and together, impact other aspects of life, such as work productivity.

The purpose of our analysis was to explore the relationship between pain and fatigue with daily activity and work productivity, in patients from a randomized, double-blind, phase 3 clinical trial of baricitinib, an oral, selective inhibitor of Janus kinase (JAK)1 and JAK2 [5].

\section{METHODS}

\section{Patients}

This is a post hoc analysis of the baricitinib clinical trial, RA-BEAM (NCT01710358), in which baricitinib $4 \mathrm{mg}$ plus methotrexate (MTX) was associated with significant clinical improvements, including pain and fatigue, over MTX plus adalimumab [6, 7]. The RA-BEAM study was approved by Quorum Review IRB \#27257. Additionally, each participating center's institutional review board or ethics committee approved the study. The list of centers can be found in the first RA-BEAM publication. The study was conducted in accordance with ethical principles of the Declaration of Helsinki and Good Clinical Practice guidelines. All patients provided written informed consent. No additional ethical approval was required to conduct the current post hoc analysis. Results from the study have been published previously $[6,7]$. Briefly, the trial was a randomized, double-blind, double-dummy, placebo-controlled and active-controlled, parallel-arm, 52-week study. Patients $(n=1,305)$ on stable background MTX were randomly allocated (3:2:3) to placebo, $40 \mathrm{mg}$ of subcutaneous adalimumab every other week, or $4 \mathrm{mg}$ of baricitinib orally daily. Patients were $\geq 18$ years old with active RA $[\geq 6 / 68$ tender and $\geq 6 / 66$ swollen joints; C-reactive protein (CRP) $\geq 6 \mathrm{mg} / \mathrm{l}$. Patients had an inadequate response to MTX and were required to have either $\geq 3$ joint erosions (based on radiographs) or $>1$ joint erosion and be seropositive for rheumatoid factor or anticitrullinated peptide antibodies [7]. 


\section{Measures}

Pain was measured on a visual analogue scale (VAS), with responses ranging from $0 \mathrm{~mm}$ (no pain) to $100 \mathrm{~mm}$ (worst possible pain). The pain VAS was administered at all study visits. Reduction in pain was categorized as $<30 \%$, $30 \%$ to $<50 \%, \geq 50 \%$ pain relief at weeks 12 and 24. These thresholds were chosen based on the recommendations by the Initiative on Methods, Measurement, and Pain Assessment in Clinical Trials, a group focusing on improvements of clinical studies in chronic pain conditions [8]. Likewise, remaining pain was assessed and categorized as $\leq 10 \mathrm{~mm},>10$ to $\leq 20 \mathrm{~mm},>20$ to $\leq 40 \mathrm{~mm},>40 \mathrm{~mm}$. The $10 \mathrm{~mm}$ threshold was derived from data by Wells, et al. [9]; the $20 \mathrm{~mm}$ threshold reflects when pain does not negatively affect healthrelated QOL $[9,10]$; and the $40 \mathrm{~mm}$ threshold was based on cut-off points between the pain VAS and the Patient Acceptable Symptom State (PASS) [11].

Fatigue was assessed using the Functional Assessment of Chronic Illness Therapy-Fatigue (FACIT-F) scale, with a range from 0 to 52, with higher scores representing less fatigue [12]. A normative score for the FACIT-F is $\geq 40.1$ and the minimum clinically important difference (MCID) value of 3.56 was used to assess the clinical relevance of changes in the FACIT-F [12-14]. The FACIT-F was administered at baseline, week 4 , and every 4 weeks thereafter until week 32, and then at week 40 and week 52 . At weeks 12 and 24, the following were evaluated: the percentage of patients reporting improvement in fatigue $(<3.56, \geq 3.56)$ and the percentage of patients reporting FACIT-F normative values $(\geq 40.1)$ or not $(<40.1)$.

The Work Productivity Impairment Questionnaire-Rheumatoid Arthritis (WPAI-RA) measured work and activity impairments over the past 7 days. The instrument is composed of six questions that are calculated into four scores: normal daily activities (daily activity impairment), work-time missed due to RA (absenteeism), impairment while working due to RA (presenteeism), and overall work impairment due to RA (work productivity impairment). Scores are the percentages of impairment
(0-100\%), with higher scores denoting greater impairment [15]. The WPAI-RA was administered at baseline, week 2 , week 4 , and then followed the same schedule as the FACIT-F at later study visits. The current analysis focused on impairment of daily activity and of work productivity. Absenteeism and presenteeism, which are used to calculate work productivity impairment, are presented in the Data Supplement.

\section{Additional Variables}

In addition to pain and fatigue, we assessed the relationship between CRP, tender joint count (TJC), and swollen joint count (SJC) with the scores from the WPAI-RA.

\section{Statistical Analyses}

Data were pooled across treatment arms for analyses assessing correlation between variables described below and the relationship between pain, fatigue, and the WPAI-RA. Data from baricitinib-treated patients were analyzed alone as a sensitivity analysis and are included in the Data Supplement. Missing values were imputed using the modified last-observation carried forward method.

Spearman correlations were assessed with the change from baseline for pain VAS, FACIT-F, and other variables (CRP, SJC28, TJC28) with the WPAI-RA scores using observed data at weeks 12 and 24 . This assessment was conducted to determine which factors were more correlated with impairments in daily activity and work productivity. Spearman correlations $\leq 0.40$ were considered low correlation, 0.41 to $\leq 0.75$ were moderate correlation, and $>0.75$ were strong correlation [16].

Pairwise comparisons of improvement in WPAI-RA scores between pain $(<30 \%, 30$ to $<50 \%$, and $\geq 50 \%$ ) and between fatigue reduction groups $(<3.56$ and $\geq 3.56)$ at weeks 12 and 24 were assessed by ANCOVA adjusting for geographical region, baseline joint erosion status, and baseline values of WPAI-RA scores.

Because pain, fatigue, and disease activity, defined by Disease Activity Score 28-joint 
count-CRP (DAS28-CRP), may impact daily activity and work productivity, we conducted a mediation analysis to assess their relative contribution to improvements in daily activity and work productivity by treatment over placebo at weeks 12 and 24 [17]. In the mediation analysis, the dependent variable was the improvement from baseline to week 12 or 24 for daily activity or work productivity. The treatment (baricitinib vs. placebo or adalimumab vs. placebo) was the independent variable. Changes in pain, fatigue, and DAS28-CRP from baseline to week 12 or week 24 were used as the mediator variables. The total treatment effect on daily activity or work productivity over placebo that can be accounted for by changes in pain, fatigue, and DAS28-CRP is the "indirect" or mediation effect; whereas, the total treatment effect that cannot be accounted for by the mediation effect is the "direct" effect (Figure S1).

Statistical analyses were performed with SAS (SAS Institute; Cary, NC, version 9.4). A twosided $p$ value $<0.05$ was considered statistically significant. $P$-values were not adjusted for multiple comparisons.

\section{RESULTS}

\section{Baseline Patient Characteristics}

The baseline patient characteristics were similar across treatment groups [6, 7]. The majority of patients were women with a mean age of approximately 53 years. Most patients included in the trial had long disease duration, with a time from RA diagnosis of approximately 9 years. For the WPAI-RA at baseline, 545 patients $(42 \%)$ were employed. Across treatment groups, the mean baseline values ranged from 56 to $58 \%$ for impairment in daily activities, $12-13 \%$ for absenteeism, $42-46 \%$ for presenteeism, and $45-49 \%$ for work productivity impairment (Table S1, Table 2).

\section{Correlation Analyses}

When all the patient data were combined, correlation analyses indicated statistically
Table 1 Spearman correlation between pain, fatigue, CRP, SJC28, and TJC28 with impairment in daily activity and work productivity

\begin{tabular}{|c|c|c|}
\hline Timepoint & $\begin{array}{l}\text { Change in } \\
\text { daily activity }\end{array}$ & $\begin{array}{l}\text { Change in work } \\
\text { productivity }\end{array}$ \\
\hline \multicolumn{3}{|c|}{ Change in pain VAS } \\
\hline Week 12 & $0.51^{* * *}$ & $0.43^{* * *}$ \\
\hline Week 24 & $0.53^{* * *}$ & $0.41^{* * *}$ \\
\hline \multicolumn{3}{|c|}{ Change in FACIT-F total score } \\
\hline Week 12 & $-0.48^{* * *}$ & $-0.46^{* * *}$ \\
\hline Week 24 & $-0.47^{* * *}$ & $-0.38^{* * *}$ \\
\hline \multicolumn{3}{|c|}{ Change in CRP } \\
\hline Week 12 & $0.20^{* * *}$ & $0.19^{* * *}$ \\
\hline Week 24 & $0.15^{* * *}$ & $0.13^{*}$ \\
\hline \multicolumn{3}{|c|}{ Change in SJC28 } \\
\hline Week 12 & $0.23^{* * *}$ & $0.17^{* * *}$ \\
\hline Week 24 & $0.19^{* * *}$ & $0.15^{* *}$ \\
\hline \multicolumn{3}{|c|}{ Change in TJC28 } \\
\hline Week 12 & $0.32^{* * *}$ & $0.29^{* * *}$ \\
\hline Week 24 & $0.26^{* * *}$ & $0.22^{* * *}$ \\
\hline \multicolumn{3}{|c|}{$\begin{array}{l}{ }^{*} p \leq 0.05,{ }^{* * *} p \leq 0.001 ; \text { Spearman correlation values } \\
\text { from approximately } 0.4-0.5 \text { indicate moderate correlation; } \\
\text { whereas the correlation values from } 0.1 \text { to } 0.3 \text { indicate low } \\
\text { correlation [16] } \\
C R P \text { C-reactive protein, FACIT-F functional assessment } \\
\text { of chronic illness therapy-fatigue, SJC28 swollen joint } \\
\text { count- } 28, T J C 28 \text { tender joint count- } 28, V A S \text { visual analog } \\
\text { scale }\end{array}$} \\
\hline
\end{tabular}

significant correlations between reductions in pain and fatigue with improvements in daily activity and work productivity at both week 12 and 24 (Table 1). Specifically, the correlation (R values) for pain and fatigue ranged from 0.4 to 0.5 (moderate correlation); whereas the correlation values for CRP, SJC28, and TJC28 ranged from 0.1 to 0.3 (low correlation). Similar results were observed for baricitinib-treated patients (Table S3). 


\section{Treatment Effect upon Pain, Fatigue, and WPAI-RA at Weeks 12 and 24}

At week 12, patients treated with baricitinib and adalimumab reported statistically significantly greater improvements from baseline for both pain and fatigue compared with placebo-treated patients $(p \leq 0.001)[6]$ (Table 2$)$. For pain, the change from baseline was greater for baricitinibtreated compared with adalimumab-treated patients $(p \leq 0.01)$. Likewise, at week 12 , patients treated with baricitinib or adalimumab reported improvements in their daily activity. Baricitinib-treated patients reported improvement in work productivity compared with placebo; in contrast, there were no statistically significant differences for adalimumab compared with placebo (Table 2). Similar trends were observed at week 24 (Table 2).

\section{Association of Pain and Fatigue with Daily Activity and Work Productivity}

For all patients combined at week 12, patients with $\geq 50 \%$ reduction in pain from baseline had significantly greater improvements ( $p$ $\leq 0.001$ ) in daily activity and work productivity compared to those with less reduction in pain (Fig. 1). At week 24, patients with $\geq 50 \%$ reduction in pain from baseline reported statistically significant improvements $(p \leq 0.001)$ only in daily activity compared to those with less pain reduction. Similar findings were observed for baricitinib-treated patients at weeks 12 and 24 (Figure S3).

At weeks 12 and 24, patients who had a clinically relevant change in fatigue, a FACIT-F MCID of $\geq 3.56$ from baseline, also experienced significantly greater improvements in daily activity and work productivity compared to those who did not achieve the MCID (Fig. 1). Similar results were observed among baricitinibtreated patients (Fig. 1, Figure S5).

At weeks 12 and 24, those patients who reported values that met or exceeded the "normal" value of fatigue (FACIT-F $\geq 40.1$ ) and the lowest levels of remaining pain (pain VAS $\leq 10 \mathrm{~mm}$ ), reported approximately $30 \%$ improvement in daily activities (Fig. 2). For each increasing level of remaining pain, improvement in daily activity decreased. Additionally, patients with less fatigue tended to report greater improvement in daily activity compared to those who reported more fatigue.

At the lowest levels of remaining pain $(\leq 10 \mathrm{~mm})$, fatigue did not appear to affect work productivity. For example, at week 12, among patients with minimal remaining pain $(\leq 10 \mathrm{~mm})$, the percentage of improvement in work productivity was $26 \%$ and $31 \%$ for those with low $(\geq 40.1)$ and higher $(<40.1)$ levels of fatigue, respectively. With increasing levels of pain $(>10 \mathrm{~mm})$, levels of fatigue tended to have a greater relationship with work productivity improvement (Fig. 2, Figure S5).

\section{Mediator Analysis}

The total effect of baricitinib over placebo on daily activity or work productivity tended to be greater than that for adalimumab over placebo at both weeks 12 and 24 (Fig. 3). In the mediation analysis, the contributions of pain, fatigue, and disease activity by treatment on daily activity or work productivity represented the combined 'indirect effect' or the mediation effect while the total treatment effect on daily activity or work productivity that is not accounted for by the mediation effect is called 'direct effect'. The mediation effect accounted for the majority of the total effect (indirect and direct effect combined) in improvements in daily activity or work productivity over placebo at weeks 12 or 24 (Fig. 3).

\section{DISCUSSION}

The burden of RA for patients in this trial was high in terms of baseline impairments in daily activity and work productivity. Specifically, across all patients at baseline, the daily activity impairment was $>50 \%$. Of the 545 patients who were employed at baseline, the work productivity impairment ranged from 45 to $49 \%$. Treatment with baricitinib or adalimumab resulted in reductions of pain and fatigue and improvements in daily activity and work productivity compared to placebo. In our analyses, 


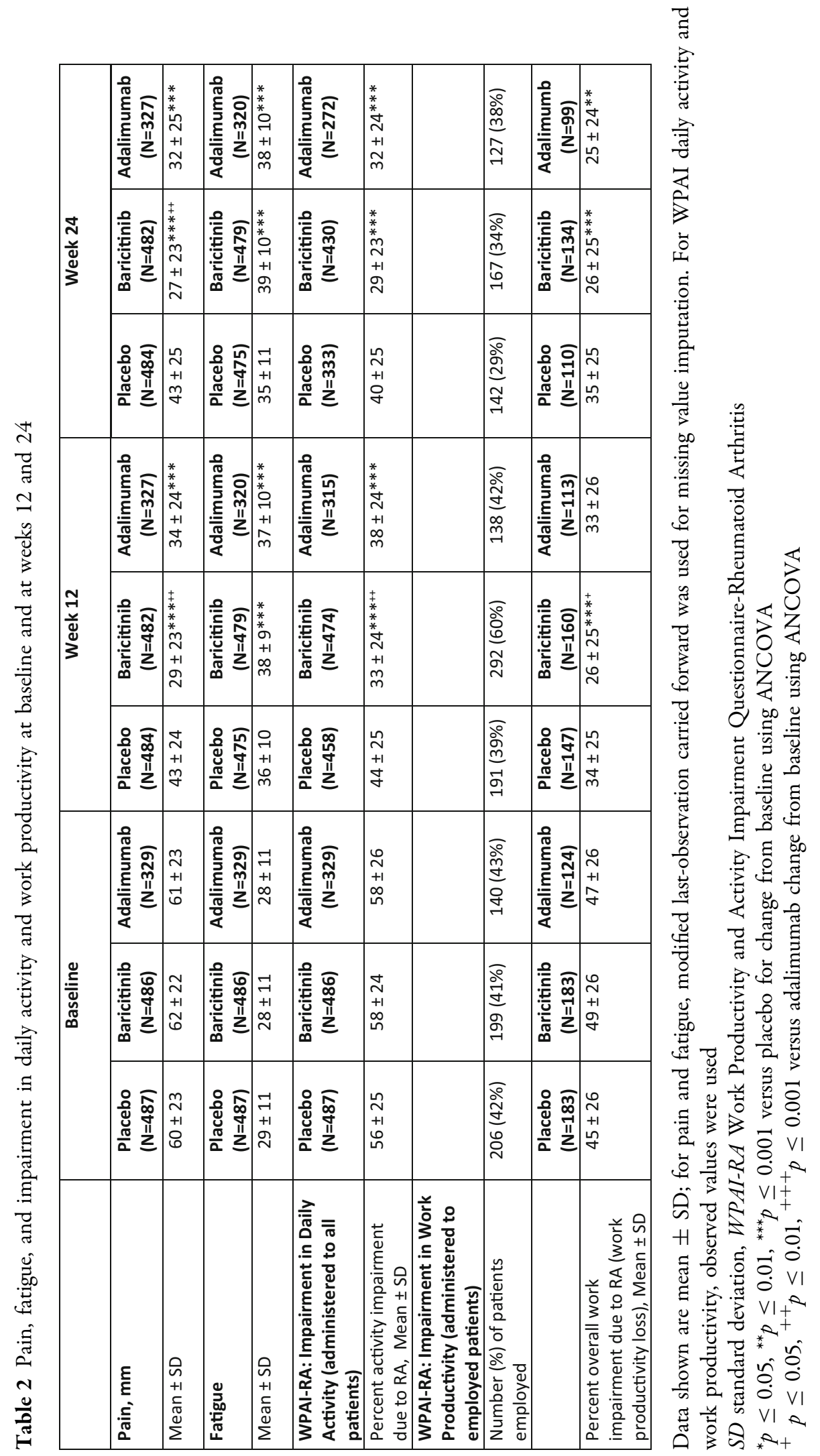





Fig. 1 a The relationship of pain and fatigue with improvement in daily activity at weeks 12 and 24 . ${ }^{*} p \leq 0.05,{ }^{* *} p \leq 0.01,{ }^{* * *} p \leq 0.001$ vs. $<30 \%$ pain reduction; ${ }^{\dagger} p \leq 0.05,{ }^{\dagger \dagger} p \leq 0.01,{ }^{\dagger \dagger \dagger} p \leq 0.001$ vs. 30 to $<50 \%$ pain reduction. $\mathbf{b}$ The relationship of pain and

fatigue with improvement in work productivity at weeks 12 and $24 .{ }^{*} p \leq 0.05,{ }^{* *} p \leq 0.01,{ }^{* * *} p \leq 0.001$ vs. $<30 \%$ pain reduction; ${ }^{\dagger} p \leq 0.05,{ }^{\dagger \dagger} p \leq 0.01,{ }^{\dagger \dagger \dagger} p \leq 0.001$ vs. 30 to $<50 \%$ pain reduction 
A

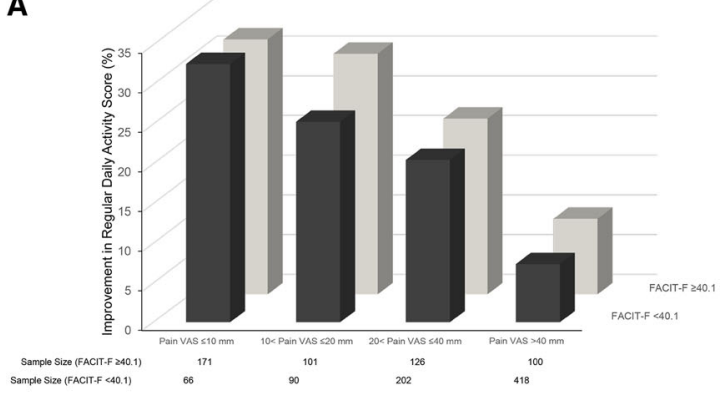

C

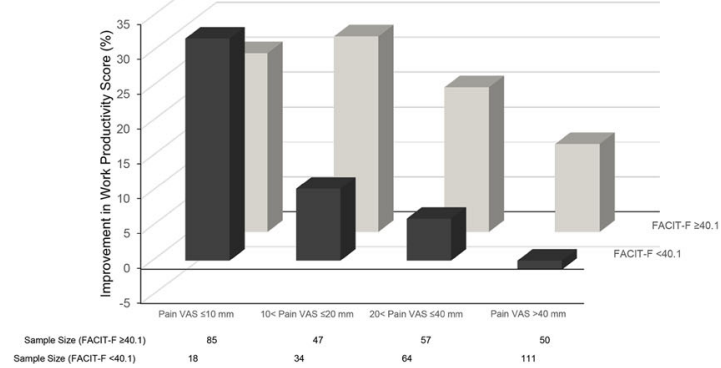

Fig. 2 a Pain, fatigue, and improvement in daily activity at week 12. b Pain, fatigue, and improvement in daily activity at week 24. c Pain, fatigue, and improvement in work

we observed that pain and fatigue tended to be more correlated with daily activity and work productivity, compared to other measures, such as CRP, TJC, and SJC, thus confirming the feasibility of focusing on pain and fatigue as factors for impairments in daily activity and work productivity. Pain and fatigue had significant independent effects on daily activity and work productivity over 24 weeks of treatment. When pain and fatigue were evaluated together, we observed that at the lowest level of remaining pain, work productivity improvement was not influenced by fatigue. At higher levels of remaining pain, however, the data suggested that both pain and fatigue have an impact on patient's work productivity. Reductions in pain and fatigue, along with low disease activity, accounted for most of the improvements in daily activity and work productivity with treatment.

Our results are consistent with prior studies that have found that pain and fatigue are contributors to productivity-related outcomes [18-22]. Our analysis, however, expands upon
B

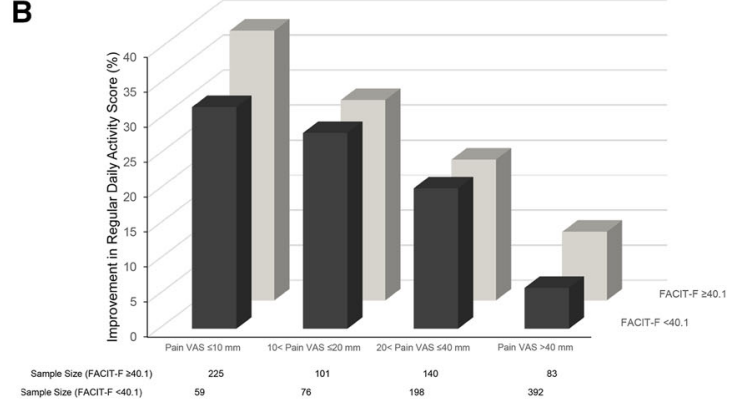

D

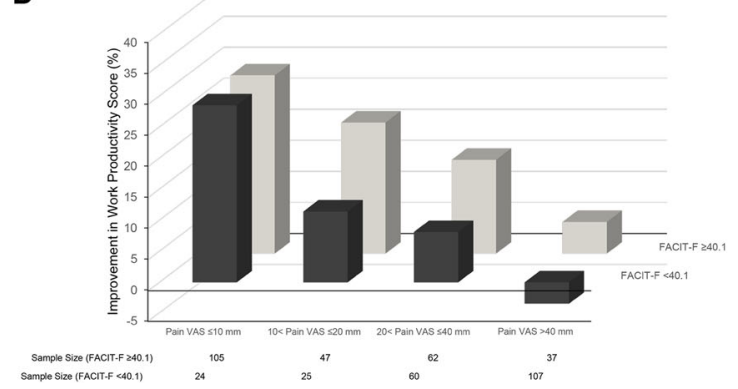

productivity at week 12 . $\mathbf{d}$ Pain, fatigue, and improvement in work productivity at week 24

prior research by demonstrating the relative contributions of pain and fatigue.

The current analysis has limitations. Because the data are derived from a clinical trial in which patients initially had long disease duration and high disease activity, the results may not be generalizable to other RA patients. Additionally, we did not capture the type of employment for the patients, which may influence patient reporting. For example, patients with RA working in an office setting may more easily adjust their work day to accommodate their symptoms compared with patients in more physically demanding work. Similarly, we may not have captured other factors that influence daily activity and work productivity.

\section{CONCLUSIONS}

Results from this analysis indicate that reductions in pain and fatigue were associated with improved daily activity and work productivity in RA regardless of treatment, and greater 
A Daily Activity

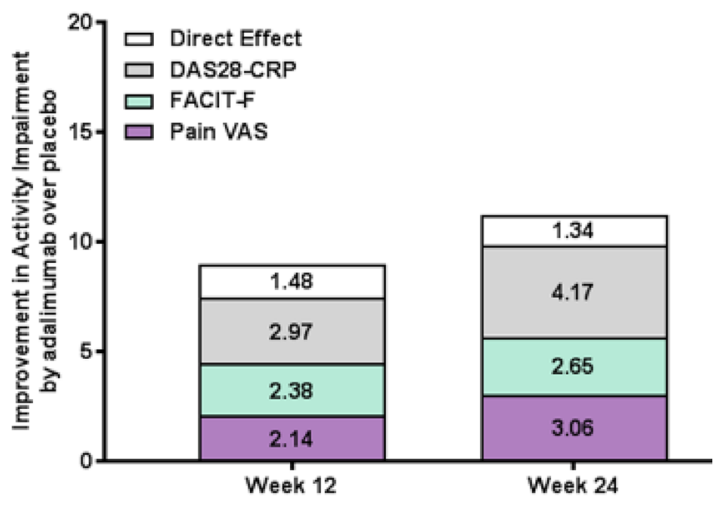

Adalimumab

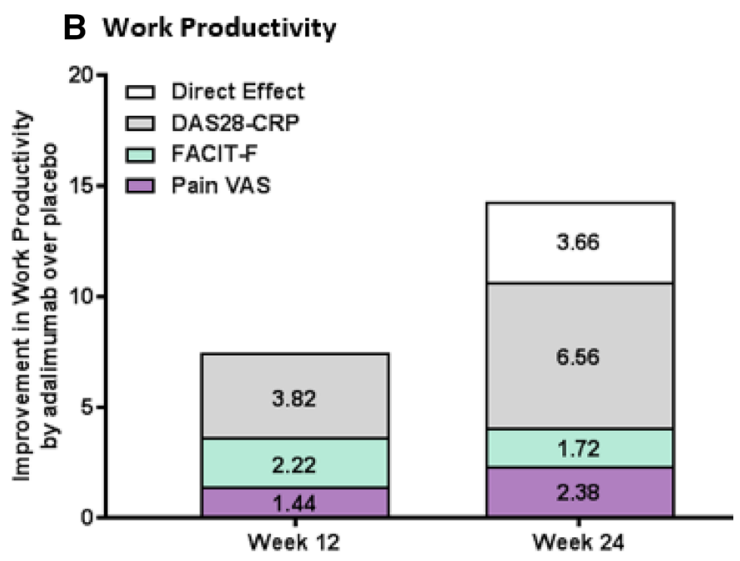

Adalimumab

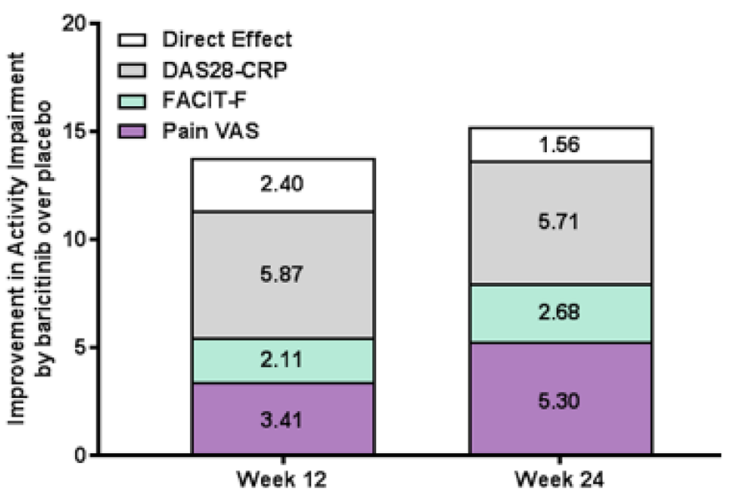

Baricitinib

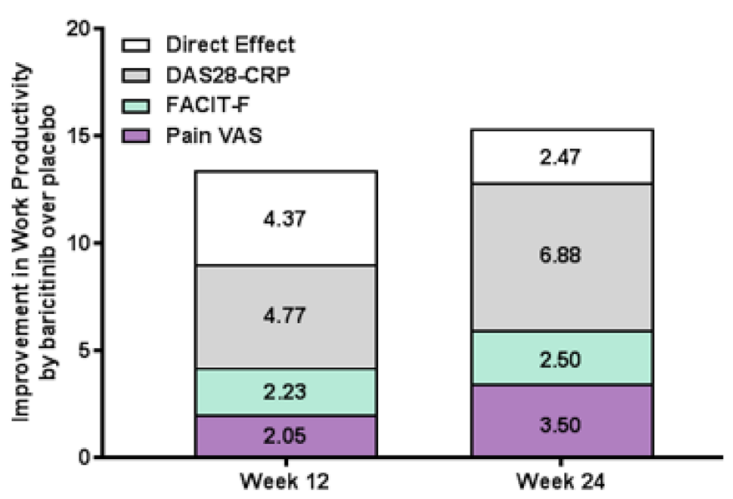

Baricitinib

DAS28-CRP: Disease Activity Score 28-joint count-CRP; FACIT-F: Functional Assessment of Chronic Illness

Therapy-Fatigue; VAS: visual analog scale

Fig. 3 Mediator analysis to assess the contribution of pain, fatigue, and disease activity on daily activity and work productivity by treatment at weeks 12 and 24

reductions resulted in more productivity. If remaining pain was minimal, however, similar levels of improvement in work productivity were observed regardless of fatigue level. These trends were also observed among baricitinibtreated patients.

\section{ACKNOWLEDGEMENTS}

Funding. This analysis was sponsored by Incyte Corporation and Eli Lilly and Company.
All authors had full access to all of the data in this study and take complete responsibility for the integrity of the data and accuracy of the data analysis.

Editorial Assistance. Editorial assistance in the preparation of this article was provided by Molly E. Tomlin, MS, and Julie Sherman of Eli Lilly and Company. Editorial assistance was funded by Eli Lilly and Company.

Authorship. All named authors meet the International Committee of Medical Journal Editors (ICMJE) criteria for authorship for this 
article, take responsibility for the integrity of the work as a whole, and have given their approval for this version to be published.

Prior Presentation. Some of the data in this manuscript have been previously presented at the Annual European Congress of Rheumatology 2018 (June 13-16, 2018; Amsterdam, Netherlands) and at the Annual Scientific Meeting of the Canadian Rheumatology Association 2019 (February 27-March 2, 2019; Montreal, Canada).

Disclosures. Kaleb Michaud has research grant funding from Pfizer and Rheumatology Research Foundation. Janet E. Pope has had research grants from Bayer, BMS, Pfizer, Merck, Roche, UCB and received honaria from AbbVie, Actelion, Amgen, Bayer, BMS, Celtrion, Lilly, Merck, Novartis, Pfizer, Roche, Sandoz, Sanofi, UCB. Paul Emery has provided expert advice for Pfizer, MSD, AbbVie, BMS, Gilead, UCB, Roche, Novartis, Samsung, Sandoz, Eli Lilly and Company. Baojin Zhu is an employee of Eli Lilly and Company. Carol L. Gaich is an employee of Eli Lilly and Company. Amy M. DeLozier is an employee of Eli Lilly and Company. Xiang Zhang is an employee of Eli Lilly and Company. Christina L. Dickson is an employee of Eli Lilly and Company. Josef F. Smolen has received grants for his institution from AbbVie, Janssen, Eli Lilly and Company, MSD, Pfizer, Roche and has provided expert advice to and/or had speaking engagements for AbbVie, Amgen, AstraZeneca, Astro, BMS, Celgene, Celtrion, Chugai, Gilead, Glaxo, ILTOO, Janssen, Eli Lilly and Company, Medimmune, MSD, NovartisSandoz, Pfizer, Roche, Samsung, Sanofi, UCB.

Compliance with Ethics Guidelines. The RA-BEAM study was approved by Quorum Review IRB \#27257. Additionally, each participating center's institutional review board or ethics committee approved the study. The list of centers can be found in the first RA-BEAM publication. The study was conducted in accordance with ethical principles of the Declaration of Helsinki and Good Clinical Practice guidelines. All patients provided written informed consent. No additional ethical approval was required to conduct the current post hoc analysis.

Data Availability. Lilly provides access to relevant anonymized patient level data from studies on approved medicines and indications as defined by the sponsor specific information on clinicalstudydatarequest.com. For details on submitting a request, see the instructions provided at clinicalstudydatarequest.com.

Open Access. This article is distributed under the terms of the Creative Commons Attribution-NonCommercial 4.0 International License (http://creativecommons.org/licenses/ by-nc/4.0/), which permits any noncommercial use, distribution, and reproduction in any medium, provided you give appropriate credit to the original author(s) and the source, provide a link to the Creative Commons license, and indicate if changes were made.

\section{REFERENCES}

1. Tillett W, Bojke L. Work disability and the cost-effectiveness of drugs to treat rheumatic diseasestime for a new dialogue? J Rheumatol. 2018;45(8):1075-7.

2. Taylor PC, Moore A, Vasilescu R, Alvir J, Tarallo M. A structured literature review of the burden of illness and unmet needs in patients with rheumatoid arthritis: a current perspective. Rheumatol Int. 2016;36(5):685-95.

3. Burton W, Morrison A, Maclean R, Ruderman E. Systematic review of studies of productivity loss due to rheumatoid arthritis. Occup Med (Lond). 2006;56(1):18-27.

4. Kim D, Kaneko Y, Takeuchi T. Importance of obtaining remission for work productivity and activity of patients with rheumatoid arthritis. J Rheumatol. 2017;44(8):1112-7.

5. Fridman JS, Scherle PA, Collins R, Burn TC, Li Y, Li $\mathrm{J}$, et al. Selective inhibition of JAK1 and JAK2 is efficacious in rodent models of arthritis: preclinical characterization of INCB028050. J Immunol. 2010;184(9):5298-307.

6. Keystone EC, Taylor PC, Tanaka Y, Gaich C, DeLozier AM, Dudek A, et al. Patient-reported outcomes from a phase 3 study of baricitinib versus placebo or 
adalimumab in rheumatoid arthritis: secondary analyses from the RA-BEAM study. Ann Rheum Dis. 2017;76(11):1853-61.

7. Taylor PC, Keystone EC, van der Heijde D, Weinblatt ME, Del Carmen Morales L, Reyes Gonzaga J, et al. Baricitinib versus placebo or adalimumab in rheumatoid arthritis. $\mathrm{N}$ Engl J Med. 2017;376(7):652-62.

8. Dworkin RH, Turk DC, Wyrwich KW, Beaton D, Cleeland CS, Farrar JT, et al. Interpreting the clinical importance of treatment outcomes in chronic pain clinical trials: IMMPACT recommendations. J Pain. 2008;9(2):105-21.

9. Wells GA, Boers M, Shea B, Brooks PM, Simon LS, Strand $\mathrm{CV}$, et al. Minimal disease activity for rheumatoid arthritis: a preliminary definition. J Rheumatol. 2005;32(10):2016-24.

10. Wolfe F, Michaud K. Assessment of pain in rheumatoid arthritis: minimal clinically significant difference, predictors, and the effect of anti-tumor necrosis factor therapy. J Rheumatol. 2007;34(8):1674-83.

11. Tubach F, Ravaud P, Martin-Mola E, Awada H, Bellamy N, Bombardier C, et al. Minimum clinically important improvement and patient acceptable symptom state in pain and function in rheumatoid arthritis, ankylosing spondylitis, chronic back pain, hand osteoarthritis, and hip and knee osteoarthritis: results from a prospective multinational study. Arthritis Care Res (Hoboken). 2012;64(11):1699-707.

12. Cella D, Yount S, Sorensen M, Chartash E, Sengupta $\mathrm{N}$, Grober J. Validation of the functional assessment of chronic illness therapy fatigue scale relative to other instrumentation in patients with rheumatoid arthritis. J Rheumatol. 2005;32(5):811-9.

13. Keystone E, Burmester GR, Furie R, Loveless JE, Emery P, Kremer J, et al. Improvement in patientreported outcomes in a rituximab trial in patients with severe rheumatoid arthritis refractory to antitumor necrosis factor therapy. Arthritis Rheum. 2008;59(6):785-93.
14. Webster K, Cella D, Yost K. The functional assessment of chronic illness therapy (FACIT) measurement system: properties, applications, and interpretation. Health Qual Life Outcomes. 2003;1:79.

15. Reilly MC, Zbrozek AS, Dukes EM. The validity and reproducibility of a work productivity and activity impairment instrument. Pharmacoeconomics. 1993;4(5):353-65.

16. Fleiss JL. Reliability of measurement. The design and analysis of clinical experiments. New York: Wiley; 1986.

17. Preacher KJ, Hayes AF. Asymptotic and resampling strategies for assessing and comparing indirect effects in multiple mediator models. Behav Res Methods. 2008;40(3):879-91.

18. Bansback N, Zhang W, Walsh D, Kiely P, Williams $\mathrm{R}$, Guh D, et al. Factors associated with absenteeism, presenteeism and activity impairment in patients in the first years of RA. Rheumatology (Oxford). 2012;51(2):375-84.

19. Druce KL, Aikman L, Dilleen M, Burden A, Szczypa $\mathrm{P}$, Basu N. Fatigue independently predicts different work disability dimensions in etanercept-treated rheumatoid arthritis and ankylosing spondylitis patients. Arthritis Res Ther. 2018;20(1):96.

20. Enns MW, Bernstein CN, Kroeker K, Graff L, Walker JR, Lix LM, et al. The association of fatigue, pain, depression and anxiety with work and activity impairment in immune mediated inflammatory diseases. PLoS ONE. 2018;13(6):e0198975.

21. Hazes JM, Taylor P, Strand V, Purcaru O, Coteur G, Mease P. Physical function improvements and relief from fatigue and pain are associated with increased productivity at work and at home in rheumatoid arthritis patients treated with certolizumab pegol. Rheumatology (Oxford). 2010;49(10):1900-10.

22. Hone D, Cheng A, Watson C, Huang B, Bitman B, Huang XY, et al. Impact of etanercept on work and activity impairment in employed moderate to severe rheumatoid arthritis patients in the United States. Arthritis Care Res (Hoboken). 2013;65(10):1564-72. 